\title{
ANALISIS INTENSITAS RADIASI MEDAN MAGNET MATAHARI
}

\author{
Sudarti ${ }^{1}$, Sherly Nur Laili1) \\ 1)Pendidikan Fisika, FKIP, Universitas Jember, Jember, Jawa Timur, Indonesia \\ Corresponding author : Sudarti \\ E-mail : sudarti.fkip@unej.ac.id
}

\section{Diterima 18 April 2021, Direvisi 04 Mei 2021, Disetujui 05 Mei 2021}

\begin{abstract}
ABSTRAK
Medan magnet ELF (Extremely Low Frequency) merupakan spektrum gelombang elektromagnetik yang frekuensinya $0-300 \mathrm{~Hz}$. Matahari sumber kehidupan yang memancarkan energinya ke bumi dalam bentuk radiasi gelombang elektromagnetik. Penelitian ini bertujuan untuk membandingkan intensitas radiasi medan magnet alamiah matahari didalam ruangan dan diluar ruangan. Jenis penelitian yang digunakan adalah penelitian eksperimen. Pengukuran intensitas radiasi medan magnet oleh matahari menggunakan alat Electromagnetic Field (EMF) Meter dan thermometer. Penelitian dilakukan mulai pukul 06.00 - 15.00 WIB dimana semakin siang temperatur medan magnet dan radiasi matahari semakin meningkat, kemudian suhu dan intensitas menurun seiring dengan terbenamnya matahari. Teknik analisa data yang digunakan menggunakan SPSS dengan metode interpretasi data. Hasil Penelitian menunjukkan data diluar ruangan memiliki hasil lebih tinggi dibandingkan dengan data hasil penelitian di dalam ruangan yakni rerata suhu didalam ruangan $29,5^{\circ} \mathrm{C}, 31^{\circ} \mathrm{C}, 32,36^{\circ} \mathrm{C}$, dan $31,7^{\circ} \mathrm{C}$ sedangkan diluar ruangan $30,9^{\circ} \mathrm{C}, 32,9^{\circ} \mathrm{C}, 33,4^{\circ} \mathrm{C}, 32^{\circ} \mathrm{C}$. Rerata medan magnet didalam ruangan sebesar $0,044,0,224,0,262$, dan 0,326, sedangkan diluar ruangan sebesar $0,098,0,324,0,418$, dan 0,398 . Data penelitian menunjukkan bahwa semakin tinggi intensitas radiasi matahari mengakibatkan temperatur bumi, dan medan magnet semakin tinggi.
\end{abstract}

Kata kunci: intensitas;matahari; medan magnet;radiasi.

\begin{abstract}
Elf magnetic field (Extremely Low Frequency) is a spectrum of electromagnetic waves whose frequency is $0-300 \mathrm{~Hz}$. Sun is a source of life that emits its energy to earth in the form of electromagnetic wave radiation. This study aims to compare the radiation intensity of natural magnetic fields by the sun indoors and outdoors. The type of research used is experimental research. Measurement of magnetic field radiation intensity by the sun using EMF Meter and thermometer. The research was conducted from $06.00-15.00$ WIB where the more daylight the temperature of the magnetic field and solar radiation increases, then the temperature and intensity decreases with the sunset. Data analysis techniques used using SPSS with data interpretation methods. The results showed that outdoor data had higher results compared to the data of indoor research results, namely the average indoor temperature of $29.5^{\circ} \mathrm{C}$, $31^{\circ} \mathrm{C}, 32.36^{\circ} \mathrm{C}$, and $31.7^{\circ} \mathrm{C}$ while outdoors $30.9^{\circ} \mathrm{C}, 32.9^{\circ} \mathrm{C}, 33.4^{\circ} \mathrm{C}, 32^{\circ} \mathrm{C}$. The average indoor magnetic field is $0.044,0.224,0.262$, and 0.326 , while outdoors is $0.098,0.324,0.418$, and 0.398 . Research data shows that the higher the intensity of solar radiation results in the Earth's temperature, and the magnetic field gets higher.
\end{abstract}

Keywords: intensity;sun; magnetic field;radiation.

\section{PENDAHULUAN}

Gelombang elektromagnetik dalam ilmu fisika merupakan gelombang yang terdiri dari medan magnet dan terdiri dari medan listrik yang dimana tidak memerlukan medium perantara dalam perambatannya. Suatu medan listrik yang tegak lurus dengan adanya medan magnet maka medan magnet dan medan listrik tersebut rambatannya tegak lurus (Young, 2012). Medan Magnet Extremely Low Frequency ini mempunyai frekuensi yang sangat rendah yakni antara $0-300 \mathrm{~Hz}$, sehingga mudah sekali untuk didapatkan dilingkungan sekitar kita tentunya yang dimana dalam keadaan aliran arus listriknya mempunyai frekuensi $0-300 \mathrm{~Hz}$ tersebut. Intensitas radiasi matahari adalah ukuran distribusi flux radiasi per-satuan luas pada suatu tempat. Intensitas radiasi tersebut memberikan informasi besar energi yang ditransfer oleh matahari pada persatuan waktu Radiasi adalah suatu pancaran energi akibat osilasi cepat medan elektromagnetik. (Saroja, et al., 2018). Hubungan energi (E) terhadap panjang gelombang dengan frekuensi f yang dinyatakan dalam persamaan; 


$$
E=\frac{h c}{\lambda}
$$

Radiasi yang berasal dari matahari sampai kepermukaan bumi melalui tiga cara yaitu radiasi langsung (direct radiation), radiasi hambur (difuse radiation), dan radiasi total (global radiation). Radiasi langsung adalah radiasi yang mencapai bumi tanpa perubahan arah atau radiasi yang diterima oleh bumi dalam arah sejajar sinar datang. Radiasi hambur adalah radiasi yang mengalami perubahan arah akibat pemantulan dan penghamburan sedangkan radiasi total adalah penjumlahan radiasi langsung dan radiasi hambur (Octavianti, 2018). Pada pengukuran terhadap radiasi matahari selama 7 hari didapatkan bahwa permukaan dinding yang mengarah ke timur, selatan, utara, dan barat mendapat paparan radiasi matahari sebesar $362,240,331,254$, dalam satuan $\mathrm{W} / \mathrm{m} 2$ (Apriyadi, et al, 2019).

Berdasarkan hasil pengamatan yang terkait dengan hal tersebut, bahwasannya telah menunjukkan angin surya, medan magnet ruang antar planet adalah medium yang membawa berbagai radiasi dan partikel dari matahari pengaruhnya sampai seluruh planet di tata surya, dan daerah pengaruh ini dinamakan heliosfer (Admiranto, 2014). Menurut Sudirman, (2020) paparan gelombang elektromagnetik seluler dapat menyebabkan peningkatan produksi Spesies Oksigen Reaktif (ROS) seperti Malondialdehyde (MDA) dan penurunan aktivitas antioksidan seperti catalase, Superoxide Dismutase (SOD) dan Gluthatione Peroxidase (GSH). Jumlah ROS yang melebihi antioksidan pelindung dalam tubuh dapat menyebabkan stres oksidatif, kerusakan sel, dan jaringan. Kemudian pada hasil penelitiapenelitian lainnya menunjukkan bahwasannya serat kaca dan bahan POP-1 film mika biru memiliki penyerapan UV-B yang sangat kuat yaitu lebih dari 90\%. Sementara materi film mika lainnya memiliki berbagai penyerapan UVB di awal dan di akhir berbagai spektrum UV-B dengan nilai 70\%. Materi film Blue Mica POP-1 memiliki penyerapan sekitar $94 \%$. Materi film mika NIPON hijau memiliki penyerapan $86 \%$ di awal spektrum dan sekitar $82 \%$ di akhir. Penyerapan bahan terhadap radiasi UV-B tidak linier dengan peningkatan panjang gelombang (Sudarti, 2018).

Analisis intensitas radiasi medan magnet matahari dilakukan untuk membandingkan keadaan suhu yang dukur didalam ruangan dan diluar ruangan yang dijadikan parameter mengetahui nilai dari intensitas radiasi medan magnet matahari.

\section{METODE PENELITIAN}

Penelitian dilakukan pada semester genap tahun ajaran 2020/2021 diruang terbuka Lembaga Bimbingan Belajar Galileo Jalan Mastrip No.6 Kota Jember sebagai lokasi untuk mengukur intensitas radiasi medan magnet terhadap matahari. Penelitian dilakukan mulai pukul 06.00 - 15.00 WIB bulan maret 2021, dimana semakin siang temperatur medan magnet dan radiasi matahari semakin meningkat, kemudian suhu dan intensitas menurun seiring dengan terbenamnya matahari. Pengukuran dilakukan pada jam ke 06.00, 09.00, 12.00, 15.00 WIB. Setiap satu perlakuan dilakukan 5 kali pengukuran. Jenis penelitian yang digunakan dalam penelitian ini adalah eksperimen dengan menggunakan alat EMF meter untuk mengukur berapa intensitas radiasi medan magnet yang dihasilkan oleh matahari dalam waktu tertentu. Adapun alat yang digunakan dalam pelaksanaan penelitian yaitu : EMF tester tipe Lutron EMF-827 untuk mengukur besarnya medan magnet yang dihasilkan dari matahari, thermometer digunakan sebagai alat pengukur suhu.

Metode penelitian yang dilakukan melalui pengumpulan data secara langsung dengan prosedur penelitian dibawah ini :

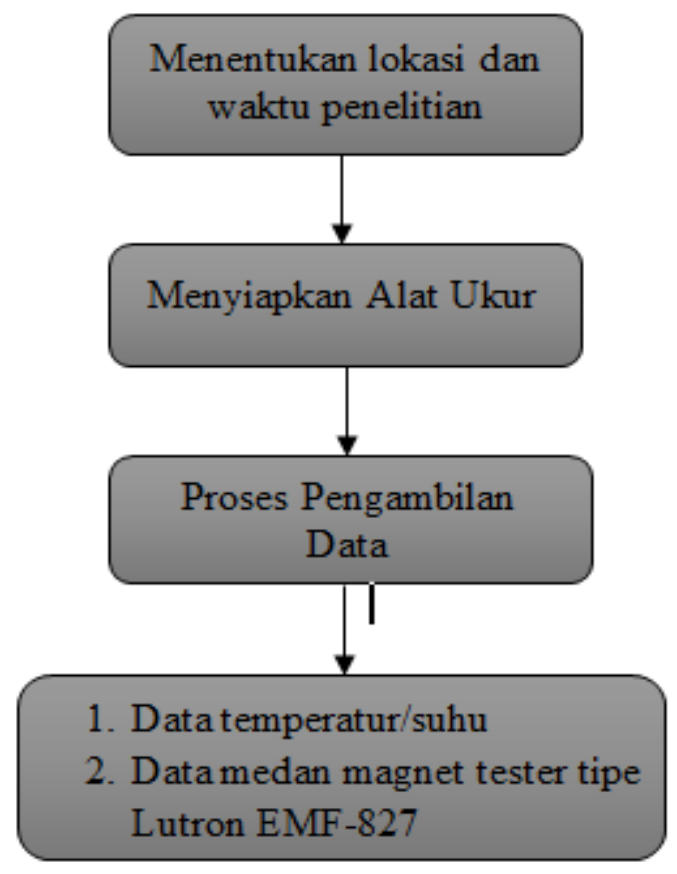

Gambar 1.Prosedur penelitian 


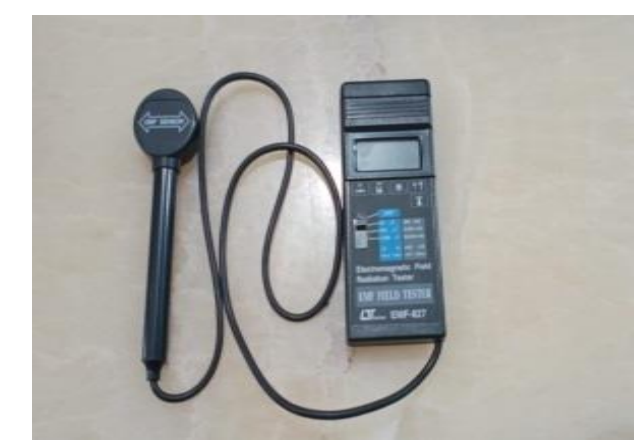

Gambar 2. EMF tester tipe Lutron EMF-827

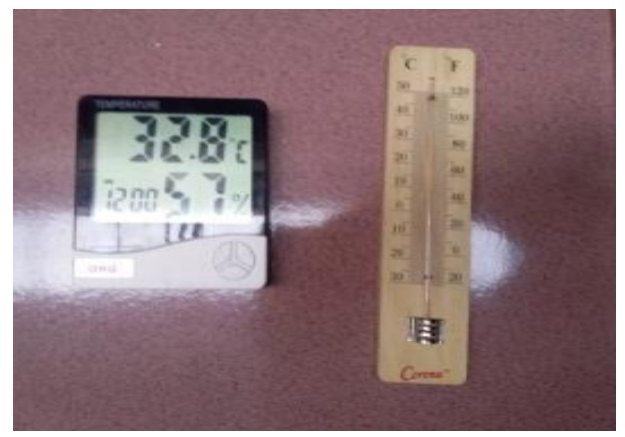

Gambar 3. Thermometer Digital/Ruangan

HASIL DAN PEMBAHASAN

Tabel 1. Data Suhu Hari Pertama

\begin{tabular}{cccc}
\hline \multicolumn{4}{c}{ Didalam Ruangan } \\
\hline $\mathbf{0 6 . 0 0}$ & $\mathbf{0 9 . 0 0}$ & $\mathbf{1 2 . 0 0}$ & $\mathbf{1 5 . 0 0}$ \\
29 & 31 & 32,8 & 31 \\
29 & 31 & 33 & 32,2 \\
30,5 & 31 & 32 & 32,3 \\
29 & 31,8 & 33 & 31 \\
30 & 31 & 31 & 32 \\
\hline
\end{tabular}

Tabel 2. Data Suhu Hari Pertama

\begin{tabular}{cccc}
\hline \multicolumn{4}{c}{ Diluar Ruangan } \\
\hline $\mathbf{0 6 . 0 0}$ & $\mathbf{0 9 . 0 0}$ & $\mathbf{1 2 . 0 0}$ & $\mathbf{1 5 . 0 0}$ \\
31 & 33 & 34 & 31 \\
31,5 & 32 & 33 & 32,5 \\
31 & 33 & 33 & 32,5 \\
30 & 33,5 & 34,2 & 32 \\
31 & 33 & 33 & 32 \\
\hline
\end{tabular}

Pada data penelitian diatas maka dapat diketahui bahwa hari pertama pada lokasi luar ruangan tepatnya di depan Kantor Lembaga Bimbingan Belajar Galileo Sumbersari Kabupaten Jember dan pada lokasi dalam ruangan Ruang Kelas $\mathrm{H}$ non-Ac pada pukul 06.00 didapatkan rata-rata suhu di dalam ruangan sebesar $29,5^{\circ} \mathrm{C}$, sedangkan untuk di luar ruangan sebesar $30,9^{\circ} \mathrm{C}$. Pada pukul 09.00 didapatkan rata-rata suhu di dalam ruangan sebesar $31^{\circ} \mathrm{C}$, sedangkan untuk luar ruangan $32,9^{\circ} \mathrm{C}$. Pada pukul 12.00 didapatkan rata-rata suhu di dalam ruangan sebesar $32,36{ }^{\circ} \mathrm{C}$, sedangkan untuk luar ruangan $33,4{ }^{\circ} \mathrm{C}$. Pada pukul 15.00 didapatkan rata-rata suhu di dalam ruangan sebesar $31,7^{\circ} \mathrm{C}$, sedangkan untuk di luar ruangan sebesar $32{ }^{\circ} \mathrm{C}$ dengan suasana keadaan hujan.

Tabel 3. Data Suhu Hari Kedua

\begin{tabular}{cccc}
\hline \multicolumn{4}{c}{ Didalam Ruangan } \\
\hline $\mathbf{0 6 . 0 0}$ & $\mathbf{0 9 . 0 0}$ & $\mathbf{1 2 . 0 0}$ & $\mathbf{1 5 . 0 0}$ \\
28 & 31 & 32 & 31 \\
29 & 30 & 33 & 31 \\
28,8 & 31,2 & 33,5 & 30 \\
29 & 30 & 33 & 30 \\
28 & 30 & 33,8 & 31 \\
\hline
\end{tabular}

Tabel 4. Data Suhu Hari Kedua

\begin{tabular}{cccc}
\hline \multicolumn{4}{c}{ Diluar Ruangan } \\
\hline $\mathbf{0 6 . 0 0}$ & $\mathbf{0 9 . 0 0}$ & $\mathbf{1 2 . 0 0}$ & $\mathbf{1 5 . 0 0}$ \\
30 & 34 & 34 & 32 \\
31 & 33 & 34 & 33 \\
31 & 32,5 & 33,8 & 34 \\
30,5 & 34 & 35,2 & 33 \\
31 & 33 & 34,5 & 33 \\
\hline
\end{tabular}

Pada data penelitian diatas maka dapat diketahui bahwa hari kedua pada lokasi luar ruangan tepatnya di depan Kantor LBB Galileo Sumbersari Kabupaten Jember dan pada lokasi dalam ruangan Ruang Kelas $\mathrm{H}$ pada pukul 06.00 didapatkan rata-rata suhu di dalam ruangan sebesar $28,5^{\circ} \mathrm{C}$, sedangkan untuk di luar ruangan sebesar $30,7^{\circ} \mathrm{C}$. Pada pukul 09.00 didapatkan rata-rata suhu di dalam ruangan sebesar $30,4^{\circ} \mathrm{C}$, sedangkan untuk luar ruangan $33,3^{\circ} \mathrm{C}$. Pada pukul 12.00 didapatkan rata-rata suhu di dalam ruangan sebesar $33{ }^{\circ} \mathrm{C}$, sedangkan untuk luar ruangan $34,3{ }^{\circ} \mathrm{C}$. Pada pukul 15.00 didapatkan rata-rata suhu di dalam ruangan sebesar $30,6{ }^{\circ} \mathrm{C}$, sedangkan untuk di luar ruangan sebesar $33{ }^{\circ} \mathrm{C}$ dengan suasana keadaan hujan.

Tabel 5. Nilai Ukur Medan Magnet Hari-1

\begin{tabular}{cccc}
\hline \multicolumn{4}{c}{ Didalam Ruangan } \\
\hline $\mathbf{0 6 . 0 0}$ & $\mathbf{0 9 . 0 0}$ & $\mathbf{1 2 . 0 0}$ & $\mathbf{1 5 . 0 0}$ \\
0,01 & 0,18 & 0,23 & 0,28 \\
0,02 & 0,23 & 0,26 & 0,27 \\
0,03 & 0,22 & 0,27 & 0,38 \\
0,07 & 0,24 & 0,28 & 0,32 \\
0,09 & 0,25 & 0,27 & 0,38 \\
\hline
\end{tabular}

Tabel 6. Nilai Ukur Medan Magnet Hari-1

\begin{tabular}{cccc}
\hline \multicolumn{4}{c}{ Diluar Ruangan } \\
\hline $\mathbf{0 6 . 0 0}$ & $\mathbf{0 9 . 0 0}$ & $\mathbf{1 2 . 0 0}$ & $\mathbf{1 5 . 0 0}$ \\
0,08 & 0,27 & 0,35 & 0,40 \\
0,12 & 0,35 & 0,42 & 0,32 \\
0,11 & 0,29 & 0,32 & 0,45 \\
0,08 & 0,42 & 0,54 & 0,35 \\
0,10 & 0,29 & 0,46 & 0,47 \\
\hline
\end{tabular}

Besar medan magnet pada uji eksperimen hari pertama menggunakan alat EMF Meter dengan menggunakan alat EMF bewarna hitam skala $20 \mu T$, data yang 
diperoleh dari penelitian tersebut adalah pada lokasi di luar ruangamn dan di dalam ruangan pada pukul 06.00 didapatkan rata-rata medan magnet di dalam ruangan sebesar 0,044, sedangkan untuk di luar ruangkan 0,098. Pada pukul 09.00 didapatkan rata-rata medan magnet di dalam ruangan sebesar 0,224, sedangkan untuk di luar ruangan 0,324. Pada pukul 12.00 didapatkan rata-rata medan magnet di dalam ruangan sebesar 0,262, sedangkan untuk di luar ruangan 0,418 . Pada pukul 15.00 didapatkan rata-rata medan magnet di dalam ruangan sebesar 0,326, sedangkan untuk di luar ruangan 0,398.

Tabel 7. Nilai Ukur Medan Magnet Hari-2

\begin{tabular}{cccc}
\hline \multicolumn{4}{c}{ Didalam Ruangan } \\
\hline $\mathbf{0 6 . 0 0}$ & $\mathbf{0 9 . 0 0}$ & $\mathbf{1 2 . 0 0}$ & $\mathbf{1 5 . 0 0}$ \\
0,02 & 0,19 & 0,25 & 0,27 \\
0,03 & 0,20 & 0,23 & 0,37 \\
0,06 & 0,22 & 0,27 & 0,34 \\
0,07 & 0,24 & 0,26 & 0,29 \\
0,07 & 0,22 & 0,27 & 0,32 \\
\hline
\end{tabular}

Tabel 8. Nilai Ukur Medan Magnet Hari-2

\begin{tabular}{cccc}
\hline \multicolumn{4}{c}{ Diluar Ruangan } \\
\hline $\mathbf{0 6 . 0 0}$ & $\mathbf{0 9 . 0 0}$ & $\mathbf{1 2 . 0 0}$ & $\mathbf{1 5 . 0 0}$ \\
0,11 & 0,29 & 0,35 & 0,32 \\
0,08 & 0,27 & 0,32 & 0,35 \\
0,11 & 0,42 & 0,46 & 0,37 \\
0,12 & 0,32 & 0,37 & 0,45 \\
0,10 & 0,27 & 0,42 & 0,35 \\
\hline
\end{tabular}

Besar medan magnet pada uji eksperimen hari kedua menggunakan alat EMF Meter dengan menggunakan alat EMF bewarna hitam skala $20 \mu T$, data yang diperoleh dari penelitian tersebut adalah pada lokasi di luar ruangan dan di dalam ruangan pada pukul 06.00 didapatkan rata-rata medan magnet di dalam ruangan sebesar 0,05 , sedangkan untuk di luar ruangkan 0,104 . Pada pukul 09.00 didapatkan rata-rata medan magnet di dalam ruangan sebesar 0,214, sedangkan untuk di luar ruangan 0,314. Pada pukul 12.00 didapatkan rata-rata medan magnet di dalam ruangan sebesar 0,256 , sedangkan untuk di luar ruangan 0,384 . Pada pukul 15.00 didapatkan rata-rata medan magnet di dalam ruangan sebesar 0,318 , sedangkan untuk di luar ruangan 0,368 .

\section{Grafik Pengukuran Suhu}

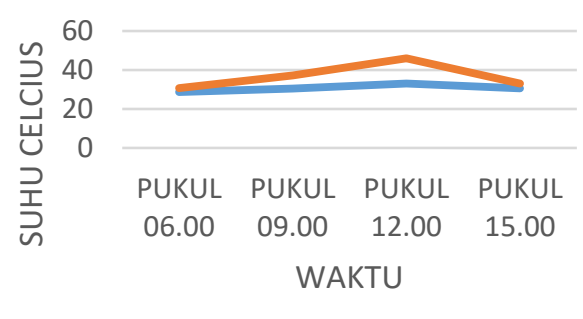

di dalam ruangan

di luar ruangan

Gambar 4. Grafik Rerata Suhu

Pengukuran temperature/suhu dilakukan dengan menggunakan 2 jenis thermometer yaitu Thermometer ruangan dan thermometer digital. Dari data yang diperoleh dan dari grafik diatas maka diketahui semakin siang waktu yang maka akan semakin panas atau suhu semakin naik. Titik puncak kenaikan suhu mulai terjadi ketika pukul $09.00 \mathrm{ke}$ atas dan puncaknya pada pukul 12.00 WIB. Akan tetapi pada saat melakukan penelitian pada hari pertama sinar matahari tertutup oleh awan dan langit dalam keadaan mendung. Dan pada pukul 15.00 suhu atau temperature baik di dalam ruangan atau di luar ruangan mengalami penurunan yang diakibatkan oleh terjadinya hujan. Akan tetapi pada hari kedua penelitian langit cerah berawan dan titik puncak terjadi pada pukul 12.00 WIB suhu mencapai $35^{\circ} \mathrm{C}$. sedangkan jika waktu semakin sore suhu akan mengalami penurunan seiring dengan tenggelamnya matahari.

Tabel 9. Hasil Uji Nonparametric test One Sample K-S pada suhu hari-1

ANOVAa

\begin{tabular}{|r|r|r|r|r|r|}
\hline Model & $\begin{array}{c}\text { Sum } \\
\text { of } \\
\text { Squar } \\
\text { es }\end{array}$ & df & $\begin{array}{c}\text { Mean } \\
\text { Squa } \\
\text { re }\end{array}$ & $\mathrm{F}$ & $\begin{array}{c}\text { Sig } \\
.\end{array}$ \\
\hline $\begin{array}{l}\text { Regr } \\
\text { essio } \\
\mathrm{n}\end{array}$ & 3,876 & 1 & 3,876 & $\begin{array}{r}10, \\
522\end{array}$ & $\begin{array}{r}\text {,08 } \\
3^{\mathrm{b}}\end{array}$ \\
$\begin{array}{l}\text { Resi } \\
\text { dual } \\
\text { Total }\end{array}$ &, 737 & 2 &, 368 & & \\
\hline
\end{tabular}

a. Dependent Variable: Suhu didalam ruangan

b. Predictors: (Constant), Suhu diluar ruangan 
Tabel 10. Hasil Uji Distribusi Normal pada suhu hari ke-1

One-Sample Kolmogorov-Smirnov Test

\begin{tabular}{|ll|r|}
\hline & & $\begin{array}{c}\text { Unstanda } \\
\text { rdized } \\
\text { Residual }\end{array}$ \\
\hline $\mathrm{N}$ & Mean &, 0000000 \\
Normal & Std. &, 4955853 \\
Parameters $\mathrm{a}, \mathrm{b}$ & 0 \\
& Deviation &, 305 \\
Most Extreme & Absolute &, 305 \\
Differences & Positive &,- 246 \\
& Negative &, 305 \\
Test Statistic & &., $\mathrm{d}$ \\
Asymp. Sig. (2-tailed) &
\end{tabular}

a. Test distribution is Normal.

b. Calculated from data.

c. Lilliefors Significance Correction.

d. Significance can not be computed because sum of case weights is less than

Berdasarkan tabel 10 diatas dapat diketahui bahwa nilai signifikansi Asiymp.sih (2-tailed) sebesar 0,305 lebih besar dari 0,05 . Maka sesuai dengan dasar uji normalitas kolmogorov-smirnov diatas, dapat disimpulkan bahwa data suhu pada eksperimen hari pertama berdistribusi normal.

Tabel 11. Hasil Uji Nonparametric test One Sample K-S pada suhu hari-2

\section{ANOVA $^{\mathrm{a}}$}

\begin{tabular}{|c|c|c|c|c|c|}
\hline Model & $\begin{array}{c}\text { Sum } \\
\text { of } \\
\text { Squ } \\
\text { ares }\end{array}$ & df & $\begin{array}{c}\text { Mea } \\
n \\
\text { Squ } \\
\text { are } \\
\end{array}$ & $\mathrm{F}$ & \\
\hline $\begin{array}{ll}1 & \text { Reg } \\
\text { ress }\end{array}$ & $\begin{array}{r}10,0 \\
0\end{array}$ & 1 & 10,0 & 7,3 &, 1 \\
\hline ion & & & 28 & & \\
\hline $\begin{array}{l}\text { Res } \\
\text { idua }\end{array}$ & $\begin{array}{r}2,72 \\
2\end{array}$ & 2 & $\begin{array}{r}1,36 \\
1\end{array}$ & & \\
\hline $\begin{array}{l}\text { Tot } \\
\text { al }\end{array}$ & $\begin{array}{r}12,7 \\
50\end{array}$ & 3 & & & \\
\hline
\end{tabular}

a. Dependent Variable: Suhu Didalam Ruangan

b. Predictors: (Constant), Besar Medan Magnet Diluar Ruangan
Tabel 12. Hasil Uji Distribusi Normal pada suhu hari ke-2

One-Sample Kolmogorov-Smirnov Test

\begin{tabular}{|ll|r|}
\hline & & $\begin{array}{r}\text { Unstand } \\
\text { ardized } \\
\text { Residual }\end{array}$ \\
\hline $\mathrm{N}$ & & 4 \\
Normal & Mean &, 000000 \\
Parameters ${ }^{\mathrm{a}, \mathrm{b}}$ & & 0 \\
& Std. &, 952579 \\
& Deviatio & 34 \\
Most Extreme & Absolute &, 293 \\
Differences & Positive &, 293 \\
& Negative &,- 207 \\
Test Statistic & &, 293 \\
Asymp. Sig. (2-tailed) & $. \mathrm{c}, \mathrm{d}$ \\
\hline
\end{tabular}

a. Test distribution is Normal.

b. Calculated from data.

c. Lilliefors Significance Correction.

d. Significance can not be computed because sum of case weights is less than 5 .

Berdasarkan tabel 12 diatas dapat diketahui bahwa nilai signifikansi Asiymp.sih (2-tailed) sebesar 0,293 lebih besar dari 0,05. Maka sesuai dengan dasar uji normalitas kolmogorov-smirnov diatas, dapat disimpulkan bahwa data suhu pada eksperimen hari kedua berdistribusi normal.

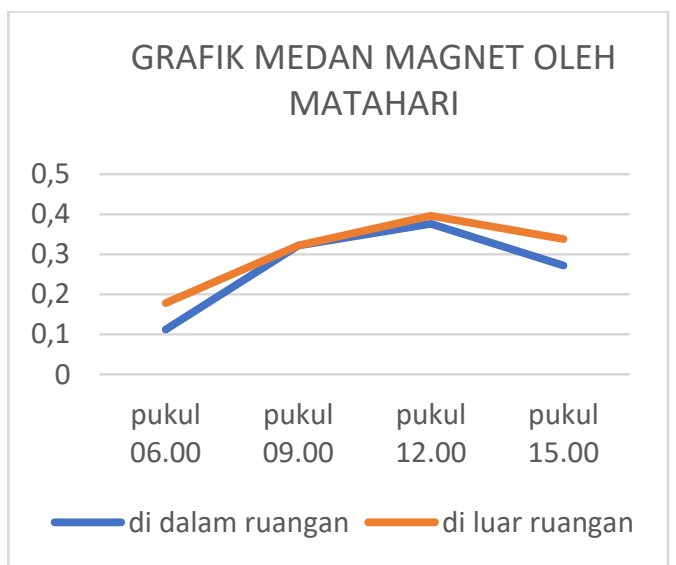

Gambar 5. Rerata Nilai Medan Magnet EMF

Pengukuran medan magnet. Besar medan magnet menggunakan Electromagnetic Field (EMF) Hitam menunjukkan di luar ruangan di depan Kantor LBB Galileo Kota Jember bahwa besarnya medan magnet yang dapat 
terbaca oleh alat ukur selalu berubah-ubah. Pada pukul 09.00 ke atas besar medan magnet yang ditunjukkan baik oleh alat EMF yang berwarna hitam sebesar 0,37 $\mu T$ dan akan naik pada pukul 12.00 besar medan magnet dapat mencapai $0,42 \mu T$.

Tabel 13. Hasil Uji Nonparametric test One Sample K-S pada medan magnet hari ke-1

ANOVA $^{a}$

\begin{tabular}{|c|c|c|c|c|c|}
\hline Model & $\begin{array}{l}\text { Sum } \\
\text { of } \\
\text { Squar } \\
\text { es }\end{array}$ & $\mathrm{df}$ & $\begin{array}{c}\text { Mean } \\
\text { Squa } \\
\text { re }\end{array}$ & $F$ & Sig \\
\hline $\begin{array}{ll}1 & \text { Regr } \\
& \text { essi } \\
& \text { on }\end{array}$ & 041 & 1 & 041 & $\begin{array}{r}25 \\
376\end{array}$ & $\begin{array}{r}, 03 \\
7^{b}\end{array}$ \\
\hline $\begin{array}{l}\text { Resi } \\
\text { dual }\end{array}$ & ,003 & 2 & ,002 & & \\
\hline Total & ,044 & 3 & & & \\
\hline
\end{tabular}

a. Dependent Variable: Besar Medan Magnet Didalam Ruangan

b. Predictors: (Constant), Besar Medan Magnet diluar ruangan

Tabel 14. Hasil Uji Distribusi Normal pada medan magnet harike-1

One-Sample Kolmogorov-Smirnov

\begin{tabular}{|ll|r|}
\multicolumn{1}{|c|}{ Test } & $\begin{array}{r}\text { Unstand } \\
\text { ardized } \\
\text { Residual }\end{array}$ \\
\hline $\mathrm{N}$ & & 4 \\
Normal & Mean &, 000000 \\
Parameters ${ }^{\mathrm{a}, \mathrm{b}}$ & & 0 \\
& Std. &, 032677 \\
& Deviatio & 10 \\
Most Extreme & Absolute &, 268 \\
Differences & Positive &, 268 \\
& Negative &,- 224 \\
Test Statistic & &, 268 \\
Asymp. Sig. (2-tailed) &., $\mathrm{d}$ \\
\hline
\end{tabular}
a. Test distribution is Normal.
b. Calculated from data.
c. Lilliefors Significance Correction.
d. Significance can not be computed because sum of case weights is less than 5 .

Berdasarkan tabel 14 diatas dapat diketahui bahwa nilai signifikansi Asiymp.sih (2-tailed) sebesar 0,268 lebih besar dari 0,05. Maka sesuai dengan dasar uji normalitas kolmogorov-smirnov diatas, dapat disimpulkan bahwa data nilai medan magnet yang diperoleh pada eksperimen hari pertama berdistribusi normal.

Tabel 15. Hasil Uji Nonparametric test One Sample K-S pada medan magnet hari ke-1

\section{ANOVA $^{a}$}

\begin{tabular}{|c|c|c|c|c|c|}
\hline Model & $\begin{array}{c}\text { Sum } \\
\text { of } \\
\text { Squa } \\
\text { res }\end{array}$ & df & $\begin{array}{c}\text { Mea } \\
\text { Squa } \\
\text { re }\end{array}$ & F & Sig \\
\hline $\begin{array}{l}\text { Reg } \\
\text { ressi } \\
\text { on }\end{array}$ &, 036 & 1 &, 036 & $\begin{array}{r}23, \\
14\end{array}$ &, 04 \\
8 & $1^{\text {b }}$ \\
$\begin{array}{l}\text { Resi } \\
\text { dual } \\
\text { Tota } \\
\text { I }\end{array}$ &, 003 & 2 &, 002 & & \\
\hline
\end{tabular}

a. Dependent Variable: Besar Medan Magnet Didalam Ruangan

b. Predictors: (Constant), Besar Medan Magnet Diluar Ruangan

Tabel 16. Hasil Uji Distribusi Normal pada medan magnet harike-2

One-Sample Kolmogorov-Smirnov Test

\begin{tabular}{|ll|r|}
\hline & & $\begin{array}{r}\text { Unstanda } \\
\text { rdized } \\
\text { Residual }\end{array}$ \\
\hline $\mathrm{N}$ & Mean & ,0000000 \\
Normal & Std. &, 0323164 \\
Parameters & Deb & 2 \\
Most Extreme & Absolute &, 239 \\
Differences & Positive &, 239 \\
& Negative &,- 166 \\
Test Statistic & &, 239 \\
Asymp. Sig. (2-tailed) &. $\mathrm{c,d}$ \\
\hline
\end{tabular}

a. Test distribution is Normal.

b. Calculated from data.

c. Lilliefors Significance Correction.

d. Significance can not be computed because sum of case weights is less than 5 .

Berdasarkan tabel 16 diatas dapat diketahui bahwa nilai signifikansi Asiymp.sih (2-tailed) sebesar 0,239 lebih besar dari 0,05. Maka sesuai dengan dasar uji normalitas kolmogorov-smirnov diatas, dapat disimpulkan bahwa data nilai medan magnet pada eksperimen hari kedua berdistribusi normal. 


\section{SIMPULAN DAN SARAN}

Berdasarkan hasil dan pembahasan yang telah disajikan, dapat disimpulkan bahwa semakin tinggi intensitas radiasi matahari mengakibatkan temperatur bumi, dan medan magnet semakin tinggi. Kemudian berdasarkan eksperimen yang telah dilakukan, maka saran yang diberikan yakni perlu dilakukannya penelitian atau uji eksperimen lebih lanjut lagi mengenai intensitas radiasi medan magnet oleh matahari.

\section{UCAPAN TERIMAKASIH}

Saya ucapkan terimakasih banyak kepada Direktur lembaga bimbingan belajar galileo atas tempat dalam pelaksanaan eksperimen atau penelitian ini. Selain itu, terimakasih juga kepada rekan-rekan yang telah berkontribusi dalam penyusunan artikel ini.

\section{DAFTAR RUJUKAN}

Admiranto, Gunawan. A. 2014. Angin Surya dan Medan Magnet Ruang Antar Planet. Faktualita, Vol. 9 (1).

Apriyadi, Syukron Dwi, Ery et al. 2019. Pengukuran Radiasi Matahari untuk Perhitungan Factor Matahari. $e$ Proceeding of Engineering, ISSN. Vol 6 (01) : 1204-1211.

Octavianti, Angelia, Muliadi dan Apriyansyah. 2018. Estimasi Intensitas Radiasi Matahari di Wilayah Kota Makassar. Jurnal Prisma Fisika, ISSN. Vol 6 (03) : 135-139.

Saroja, Ganjang et al. 2018. Estimasi Intensitas Radiasi Matahari Sesaat dengan Metode Konversi Energi. Jurnal Natural $B$, ISBN. vol 4 (03) : 135-139.

Sudarti, et al. 2018. Analysis of UV-B Absorption by Fiber Plastic/Glass with Various Colors using UV-VIS Spectrometer. International Journal of Advanced Engineering Research and Science (IJAERS), ISSN : 2349-6495, Vol 5.

Sudirman, Wahyudi Asep. 2020. Pengaruh Radiasi Gelombang Elektromagnetik Telepon Genggam Terhadap Perkembangan Sperma. Jurnal IImiah Kesehatan Sandi Husada, ISSN : 2654-4563, Vol 12 (02).

Young, H. G. (2012). College Physics 9th Edition. San Fransisco: Person Education,Inc. 